\title{
Recovery of attention with renewal
}

\author{
James Byron Nelson, ${ }^{1}$ Paul Craddock, ${ }^{2}$ Mikael Molet, ${ }^{2}$ and Charlotte Renaux ${ }^{2}$ \\ ${ }^{1}$ Departamento de Procesos Psicológicos Básicos y su Desarrollo, University of the Basque Country (UPV/EHU), San Sebastián, España \\ 20018, Spain; ${ }^{2}$ University of Lille, 59650 Villeneuve d'Ascq, France
}

\begin{abstract}
One experiment determined the relationship between renewed associative strength and attention. Following cuel-outcome pairings in Context A, cuel was extinguished in Context B while cue2 was conditioned. On test cue2 was chosen as a predictor of the outcome in Context B. Both cues were chosen equally often as predictors in Context A. Consistent with attributing attention to effective associative strength (as noted in a previous study), participants could locate only cue 2 in Context $B$ while both were located in Context A, regardless of having been chosen as a predictor. Attention varied as a function of both cues' associative strengths across contexts.
\end{abstract}

The renewal effect (e.g., Bouton and Bolles 1979) is the recovery of an extinguished conditioned response occurring with a change in the extinction context (for review, see Bouton 1993). Contexts are those incidental stimuli generally present before, during, and after, a conditioned stimulus (CS) - unconditioned stimulus (US) pairing. The effect demonstrates that a stimulus's associative strength, and resulting predictive capacity, can vary in a context-dependent manner. The present experiment was designed to determine how attention to such predictive cues changes as their meanings change across contexts.

Current theories of associative learning describe two types of attention that can be involved. Beesley et al. (2015) usefully characterize those as "attentional exploitation," which selects predictive stimuli to drive performance and "attentional exploration," which devotes resources to stimuli whose meanings are uncertain to "explore potentially useful new sources of information..." (Beesley et al., p. 2176; see also Le Pelley et al. 2016).

Attentional exploitation derives from Mackintosh (1975) where attention to stimuli is a relative function, increasing when stimuli are better predictors of USs than others. Of two predictors of a US or outcome, the one with the stronger associative strength will receive more attention relative to the weaker. Recently, Le Pelley et al. (2016) suggested that relative attention need not be considered; that a stimulus's absolute level of associative strength determines the level of attention it will command, where greater associative strength predicts greater attention.

Attentional exploration derives from Pearce and Hall (1980) where attention to stimuli decreases as their associations with a US grow. As the outcome becomes certain through being predicted by the stimulus in question, or others present on the trial, attention declines. Explorative attention covaries positively with levels of uncertainty. Variations of both processes are found in several "hybrid" attention theories (e.g., Le Pelley 2004; Haselgrove et al. 2010; Pearce and Mackintosh 2010; for review, see Le Pelley et al. 2016).

To determine how attention to a stimulus fluctuates as the meaning of the stimulus changes across contexts we used a prediction task to give stimuli meaning, along with a localization task to measure attention. Each participant was presented with ten 50-point Helvetica-bold letters, randomly selected from the alphabet. The letters appeared in a grid of boxes forming three rows and four columns on a computer screen. The middle-two boxes were removed to provide an instruction area. On each trial participants

\section{Corresponding author: JamesByron.Nelson@ehu.es; DrJBN@hotmail. com}

Article is online at http://www.learnmem.org/cgi/doi/10.1101//m.045682.117. were instructed to click the letter (one per trial) that they thought hid a pink "Smiley" face. Participants clicked a letter then all letters were removed revealing the smiley for $2 \mathrm{sec}$. For the following trial, the same letters reappeared in randomly determined positions. Timing was self-paced and the smiley appeared behind the same letter on each trial of a phase.

The design (see Table 1) was simple. Participants first associated the smiley with "Letter1," and then associated the smiley with "Letter2" in the second phase, while Letter1 was undergoing extinction. Letters 1 and 2 were randomly determined between participants. Between phases the background screen color changed from blue to yellow (or vice versa) to provide different contexts. Participants were randomly divided into two groups and tested for renewal, without interruption, following the final phase- 2 trial. In Group $\mathrm{ABB}(n=28)$, the letters were presented in Context B where extinction of Letter 1 just occurred. In Group ABA $(n=26)$ testing occurred in Context A where conditioning with Letter1 had happened previously. Participants had one opportunity to select the letter that they believed hid the smiley, then the letters disappeared without feedback. We measured the proportion of participants selecting Letter1, Letter2, and a randomly determined Letter 3 on each trial along phases 1 and 2 and the test. Renewal would be evident by more participants selecting Letter1 in Context $\mathrm{A}$ than in Context $\mathrm{B}$. There is also reason to expect that learning about Letter2 in Context B may transfer to Context A, which we will discuss later.

The localization test was $2 \mathrm{sec}$ after the selection test. On each of three randomly ordered questions participants saw the 10-box grid, now empty, and were asked to click where either Letter1, Letter2, or the randomly determined Letter3 had been placed on the preceding selection test. Clicking the wrong box prompted a "try again" message. The use of localization as an indirect measure of attention was based on Griffiths and Mitchell's (2008) reasoning that it is plausible to assume that memory for a cue will be a function of the degree of attention received by the cue. The cue's position on a trial should be better remembered when attention has been devoted to the cue. Associability, linked to exploitative attention, is also often used as an attentional index (see Le Pelley et al. 2016). High attention should facilitate participants' associating the letter with its position on each trial, facilitating recall. We

(C) 2017 Nelson et al. This article is distributed exclusively by Cold Spring Harbor Laboratory Press for the first 12 months after the full-issue publication date (see http://learnmem.cshlp.org/site/misc/terms.xhtml). After 12 months, it is available under a Creative Commons License (AttributionNonCommercial 4.0 International), as described at http://creativecommons. org/licenses/by-nc/4.0/. 
Table 1. Design of experiment

\begin{tabular}{|c|c|c|c|c|}
\hline Group & $\begin{array}{c}\text { Phase } 1 \\
\text { (Context A) }\end{array}$ & $\begin{array}{c}\text { Phase 2 } \\
\text { (Context B) }\end{array}$ & Selection test & Localization test \\
\hline ABA & \multirow{2}{*}{$\begin{array}{l}10 \text { Trials } \\
\text { Letter } 1 \rightarrow+; \\
\text { Letters } 2-10 \rightarrow \ldots\end{array}$} & \multirow{2}{*}{ 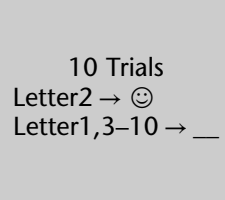 } & $\begin{array}{c}\text { Select the letter hiding } \\
\text { the }(-) \text { in Context } A\end{array}$ & $\begin{array}{l}\text { Locate the prior position } \\
\text { of Letters } 1,2 \text {, and } 3 \text { in } \\
\text { Context } A\end{array}$ \\
\hline$A B B$ & & & $\begin{array}{l}\text { Select the letter hiding } \\
\text { the }(-) \text { in Context B }\end{array}$ & $\begin{array}{l}\text { Locate the prior position } \\
\text { of Letters } 1,2 \text {, and } 3 \text { in } \\
\text { Context B }\end{array}$ \\
\hline
\end{tabular}

measured the proportion of participants localizing each letter on their first selection.

Attention paid to a stimulus is assumed to be determined by its associative strength (Le Pelley et al. 2016). Attention could depend on a cue's net acquired associative strength across the phases, or that which is currently in effect. The renewal effect shows that the effective associative strength varies by context, and the question is whether attention will also vary. In Context B where only Letter 2 should express a strong association with the outcome, its position on the test trial should be remembered better than the other letters. In Context A where Letter1's associative strength should renew, and that of Letter2 might transfer from Context B, we would see the positions of both remembered better than the other nonpredictive letters.

Phases 1 and 2 data are shown in Figure 1. Along phase 1 selection of Letter1 increased. In phase 2 selections decreased for Letter1 and increased for Letter2 (binomial exact tests, BET, Ps < $0.001)$. These changes were large effects as determined by Cramer's Phi $(\phi ' s \geq 0.6)$. Between phases there was a small effect of the context change; the Letter1 selection decreased 17\% (BET $P=0.04, \phi=0.27)$. Similar designs with humans have produced nearly identical decrements (Ungör and Lachnit 2006, 2008). Selection of Letter 1 at the start of phase 2 was, nevertheless, above that at the start of phase 1 (BET $P<0.001, \phi=0.61$ ).

The data from the renewal test are shown at the left of Figure 2. Letter1's association with the smiley was renewed in Context A and Letter2's association transferred from Context B. Letter1 was selected more often in Context A (38\%) than in Context B (4\%). Letter2 was selected less often in Context A $(31 \%)$ than in Context B (71\%, Fisher's exact tests, FET, Ps $\leq 0.006, \phi \geq 0.41)$. In Context A, selection of Letter2 equaled that of Letter1 and both were above chance (BET Ps $\leq 0.003$ ). Letter 3 was not selected in either context.

Figure 2, right, shows the proportion of participants localizing the letters on their first selection in each group. Attention to Letter1 renewed along with its associative strength. Letter 1 was localized more often in Context A (\%50) than in Context B (\%11, FET $P=0.0006 ; \phi=0.48)$. Attention to Letter2 was maintained, along with its associative strength, and it was localized equally often in Contexts A $(54 \%)$ and B $(43 \%, P=0.59 ; \phi=0.11)$. In Context A, localization of Letters 1 and 2 did not differ (BET $P=0.50 ; \phi=0$ ); each was located more frequently than Letter 3 (BET Ps $\leq 0.02, \phi \geq$ 0.43). In Context $B$, Letter 2 was localized more often than the other two letters (BET Ps $\leq 0.02 ; \phi \geq 0.42$ ). No differences were observed among Letter3 in A, Letter3 in B, and Letter1 in B $(P s=1)$.

The overall pattern of attention mirrors that of the selections made on the renewal test, but the localization data cannot be entirely explained by those selections. In Context $\mathrm{B}$, where phase- 2 selection performance was continued, $43 \%$ of the participants localized Letter2 on the first trial. Almost all of those (92\%) had also selected Letter 2 on the selection test. None had selected Letter1. In Context B, the position of the letter was best remembered by participants also exhibiting a strong letter-outcome association in their selections.
In Context A the relationship between the first-trial localization and the selection on the selection test was less clear. Letter1 and 2 were shown to be predictive and localized better than a random Letter3 (FET, Ps $\leq 0.017$ ). The majority, 69\%, localized either, or both, of Letter1 and 2. This finding is consistent with the conclusion of Le Pelley et al. (2016) that attention granted to the cues covaries positively with their associative strength. But, there was no relationship between the selection of Letters 1 or 2 and their being localized. In Context A, 50\% of the participants localized Letter1 on the first trial, but only half (54\%) of those participants had selected Letter1 on the selection test. Likewise, in Context A $54 \%$ of the participants localized Letter 2 on the first trial, but only $43 \%$ of those had also selected it. A Letter-selection (Letter1, Letter2 [Letter3 was never selected and not included]) by First-Trial Localization (yes/no) FET confirmed that localization and selection were independent for these two letters $(P=0.17)$. If only associative strength determined localization, then the cue that was ultimately selected, that with the assumed stronger association with the outcome in that context, should also have been localized better.

Both renewal with Letter1 and transfer with Letter2 are expected (see Ungör \& Lachnit 2008). Nelson and Callejas-Aguilera (2007) show that contextual control occurs best when new learning about a stimulus interferes with earlier learning across phases, as occurred with Letter1. Little contextual control of Letter2's phase- 2 performance would be expected if little had been learned about it in phase 1. If participants had clicked Letter2 during phase 1 , they could have learned an inhibitory relationship between Letter 2 and the outcome (i.e., Letter $2=$ No Smiley). Yet, in phase 1 , the majority of the participants (85\%) found the smiley under Letter1 without ever clicking Letter2. The localization data show that the more predictive stimuli command the most attention at the expense of the others. Thus, in phase 1, Letter1 would have commanded attention at the expense of the opportunity to learn

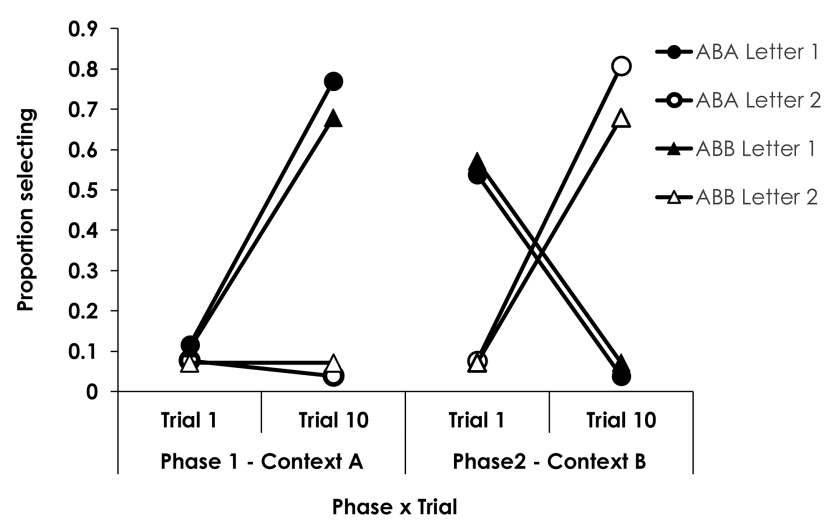

Figure 1. The proportion of participants selecting Letter 1 and Letter 2 as the predictor of the outcome at the start and end of each phase. 


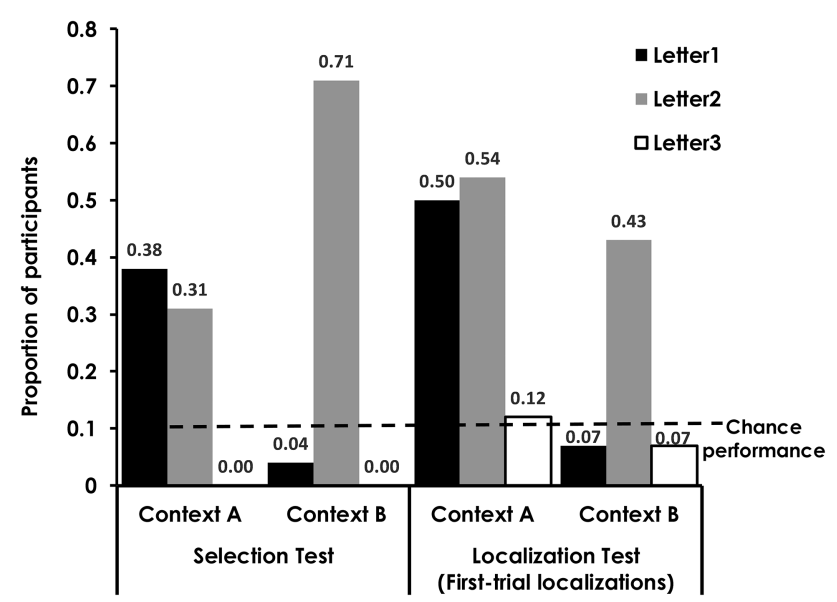

Figure 2. (Left) The proportion of participants selecting Letter1, Letter2, or Letter3 as the predictor in each group in Contexts A and B. (Right) The proportion of participants localizing each letter on their first selection on the localization test in each group. The dashed horizontal line represents chance performance.

about Letter2, protecting Letter2's phase 2 learning from contextual control.

The new result is the determination of how attention varies with renewal on the test. Attention to Letter1 renewed along with its associative strength. In Context B Letter 2 was seen as predictive as it was often selected, and Letter1 was not predictive in that it was seldom selected. Letter 2 also commanded more attention than did Letter1. In Context A, Letter1 was again seen as predictive, and it again commanded attention. In Context A Letter1 did not command more attention than Letter 2, which was shown to be as equally predictive and selected as Letter1, but both commanded more attention than a random letter or chance.

Contexts can direct attention to stimuli (e.g., Hoffman and Sebald 2005; George and Kruschke 2012). Yet, the present results suggest that the context did not operate in such a manner here. If we were to observe context-driven attention we would expect the patterns of localization on the renewal test in Context A to reflect the phase-1 training behavior with all letters. In phase 1 Letter1 was predictive, and the context should guide attention to it, while Letters2-10 were irrelevant and the context should direct attention away from them. Any control of attention established by the phase 1 context should not be affected by phase 2 , which occurred in a different context. Nevertheless, the treatment of Letter 2 in phase 2 did increase attention to Letter 2 in the phase 1 context on test. Letter1's association with the Smiley was under contextual control, as the participants had experienced conflicting outcomes with that letter across phases (e.g., Nelson 2002). Letter2's association with the smiley was not under contextual control, as they had not learned any conflicting information about it. The contexts, therefore, differentially affected the retrieval Letters1's and 2's associations on test and attention to the letters in each context resulted as a function of the currently retrieved associative strength of each letter and not from any previously established direct contextual control of attention.

In Context A two strong predictors commanded attention, indicating that attention is a function of the cue's associative strength (Le Pelley et al. 2016). Yet, with two strong predictors the participants' selection of predictors did not match their recall of their selection's position. Minimally, that latter result shows that locating the letter was not a simple artifact of having clicked it. The lack of correspondence could be due to the selection be- tween two similarly predictive cues being a somewhat random process for each participant. More interestingly, if we assume the selection is determined by the associative strength on a participant-by-participant basis, then the result may show the activity of two forms of attention. Such a possibility is consistent with the two types of attention described by Beesley et al. (2015); see also Le Pelley et al. (2016).

Exploitative attention, based on the cue's associative strength, would guide the participants to the letters in each context, and they would respond to the one with the stronger associative strength. In Context B, where only Letter 1 was predictive and should command attention, correspondence was observed between the stimulus selected and localized. In Context A where both letters were seen as predictive on test, an additional attentional process may have been affecting their processing as there was no correspondence between selection and localization. Although explorative attention is typically demonstrated by making a cue's outcome uncertain (e.g., Beesley et al. 2015), the task constraints here produced conditions where uncertainty might have existed. Due to transfer of associative strength with Letter2 and renewal of associative strength with Letter1, there were two predictors of the same outcome in Context A, and only one could be selected. The two strong predictors could produce uncertainty as to which to choose, resulting in the necessary conditions for explorative attention. The elicitation of this additional process, further directing attention to explore stimuli and their attributes, could obfuscate any differences in localization that exploitative attention alone might have produced.

Our findings on the renewal test are consistent with what is known about contextual control. Our new findings concerning attention in a renewal design support current theories of attention in human associative learning. Learning in extinction is context specific leading to expression of phase 1 associations with a change in the extinction context. Attention to stimuli appears to recover along with those associations. That recovery of attention is best described as a function of the recovery of the stimulus' associative strength rather than a direct contextual control of attention. The findings also suggest that explorative attention might additionally be evoked by the presence of multiple stimuli with high associative strengths when responses can be directed to only one.

\section{Acknowledgments}

Participation of James Byron Nelson in the research was made possible by PSI2014-52263-C2-2-P from the Ministerio de Economia, Industria, y Competitividad of Spain and grant IT-694-13 from the Basque Government.

\section{References}

Beesley T, Nguyen KP, Pearson D, Le Pelley ME. 2015. Uncertainty and predictiveness determine attention to cues during human associative learning. QJ Exp Psychol (Hove) 68: 2175-2199.

Bouton ME. 1993. Context, time, and memory retrieval in the interference paradigms of Pavlovian learning. Psychol Bull 114: 80-99.

Bouton ME, Bolles RC. 1979. Contextual control of the extinction of conditioned fear. Learn Motiv 10: 445-466.

George DN, Kruschke JK. 2012. Contextual modulation of attention in human category learning. Learn Behav 40: 530-541.

Griffiths O, Mitchell CJ. 2008. Selective attention in human associative learning and recognition memory. J Exp Psychol Gen 137: 626-648.

Haselgrove M, Esber GR, Pearce JM, Jones PM. 2010. Two kinds of attention in Pavlovian conditioning: evidence for a hybrid model of learning. J Exp Psychol Anim Behav Process 36: 456-470.

Hoffman J, Sebald A. 2005. Local contextual cuing in visual search. Exp Psychol 52: 31-38. 
Le Pelley ME. 2004. The role of associative history in models of associative learning: a selective review and a hybrid model. QJ Exp Psychol 57: 193-243.

Le Pelley ME, Mitchell CJ, Beesley T, George DN, Wills AJ. 2016. Attention and associative learning in humans: an integrative review. Psychol Bull 141: $1111-1140$.

Mackintosh NJ. 1975. A theory of attention: variations in the associability of stimuli with reinforcement. Psychol Rev 82: 276-298.

Nelson JB. 2002. Context specificity of excitation and inhibition in ambiguous stimuli. Learn Motiv 33: 284-310.

Nelson JB, Callejas-Aguilera JE. 2007. The role of interference produced by conflicting associations in contextual control. J Exp Psychol Anim Behav Process 33: 314-326.
Pearce JM, Hall G. 1980. A model for Pavlovian learning: variations in the effectiveness of conditioned but not of unconditioned stimuli. Psychol Rev 87: 532-552.

Pearce JM, Mackintosh NJ. 2010. Two theories of attention: a review and a possible integration. In Learning and attention (ed. Le Pelley ME, Mitchell CJ). Oxford University Press, Oxford, UK.

Ungör M, Lachnit H. 2006. Contextual control in discrimination reversal learning. J Exp Psychol Anim Behav Process 32: 441-453.

Ungör M, Lachnit H. 2008. Dissociations among ABA, ABC, and AAB recovery effects. Learn Motiv 39: 181-195.

Received March 30, 2017; accepted in revised form September 14, 2017. 


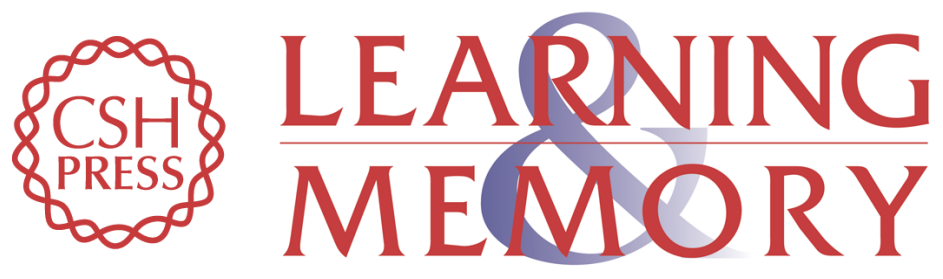

\section{Recovery of attention with renewal}

James Byron Nelson, Paul Craddock, Mikael Molet, et al.

Learn. Mem. 2017, 24:

Access the most recent version at doi:10.1101//m.045682.117

Creative Commons License

Email Alerting Service
This article is distributed exclusively by Cold Spring Harbor Laboratory Press for the first 12 months after the full-issue publication date (see

http://learnmem.cshlp.org/site/misc/terms.xhtml). After 12 months, it is available under a Creative Commons License (Attribution-NonCommercial 4.0 International), as described at http://creativecommons.org/licenses/by-nc/4.0/.

Receive free email alerts when new articles cite this article - sign up in the box at the top right corner of the article or click here. 